Funding is tight. Grants are rejected. Research equipment is too expensive. And these are complaints heard in well-heeled laboratories in the US and UK. In the following pages, we present inspiring examples of scientists who, using materials as simple as litmus paper, bamboo and blenders, prove that science on a shoestring is possible - and sometimes even better than the alternative.

\title{
Microscopes made from bamboo bring biology into focus
}

In a remote village in eastern India, dozens of underprivileged children are for the first time marveling at the elaborate details of flower petals with the help of a microscope-made out of bamboo.

Fitted with a $\times 20$ lens, the light, compact and ecofriendly microscope is proving a boon for dozens of cash-strapped schools, granting students firsthand access to an otherwise unaffordable scientific tool.

This nifty device is a product of the creative minds at Jodo Gyan, a small nonprofit in New Delhi. "Indian children are not getting to experience all the joy and wonder of science because there is too much emphasis on the

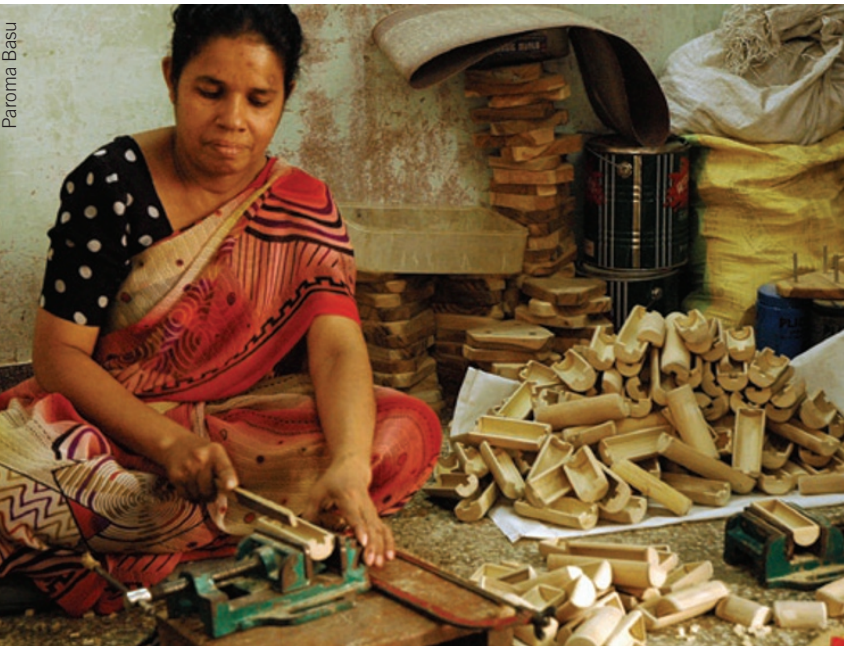

Clear vision: Members of the Delhi-based nonprofit Jodo Gyan have made about 2,500 microscopes from bamboo. memorization and repetition of concepts," says Usha Menon, a government researcher who founded Jodo Gyan in 1999. "Hundreds of thousands of children are learning without understanding anything."

Priced at 150 rupees (roughly \$4), the microscope is just one of the educational tools created by Jodo Gyan, literally translated as 'linking knowledge'. Other tools include mathematical card and board games and sticky geometric shapes in a variety of colors. The 30-member group has also led more than 700 teacher-training workshops and runs an alternative primary school that enrolls 54 underprivileged students.

But the microscope remains the star attraction. Jodo Gyan has supplied the instrument to several organizations such as Chennai's Goodbooks Teacher's Center and New Delhi's Pragya, a nonprofit that provides services to neglected, high-altitude areas. These organizations then distribute the microscopes to schools in their localities. Jodo Gyan has also secured two big orders in the last few years from the UN Children's Fund for use in alternative learning centers in India.

But with no external funding, Jodo Gyan is run on a shoestring budget, particularly because the group sells its learning aids for

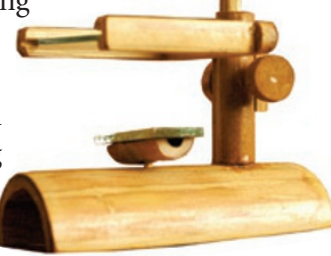
not much more than it costs to produce them, says Menon. The group's base of operations is a ramshackle building in Delhi's impoverished Shakurpur area that also doubles as Menon's home.

To meet the demand for its popular microscope, Jodo Gyan has fashioned a makeshift microscope factory right on the building's roof. Sitting up there amidst bamboo shards, members have so far chopped and carved about 2,500 microscopes for use in schools, educational nonprofits and, in at least one case, research.

Debal Deb, an ecologist who has set up a rural seed exchange to conserve dozens of endangered folk rice species in West Bengal, routinely uses Jodo Gyan's microscopes to study the surfaces of rice grains. More important, Deb's microscope has caught the attention of dozens of curious children from nearby villages, who stop by after school to peer through its lens.

"The microscope has opened up a whole new world for these children," says Deb. "They could never have imagined that an ant could have tiny antennae or that dragonfly wings could have such beautiful and intricate patterns."

Paroma Basu, New Delhi

\section{$\mathrm{pH}$ paper trumps expensive kits in measuring acidity}

Scientists in Uganda have devised a tool to test for vaginal infections that is so simple, even a child could—and did—make one.

In 2000, scientists at the Rakai Health Sciences Program in Kalisizo began studying the natural history of bacterial vaginosis, a common condition that lowers the acidity of the vagina. Using just a strip of $\mathrm{pH}$ paper, a bit of tape and a pediatric tongue depressor, they devised a 'swab' to measure vaginal $\mathrm{pH}$.

Although the test itself was simple, coming up with a working design wasn't easy. "At that time we had never measured $\mathrm{pH}$," says Mary Sullivan, a former Rakai lab manager who now coordinates hepatitis research at Johns Hopkins University.

For a previous study of sexually transmitted diseases, the researchers had shown women in nearby villages how to use cotton swabs to collect their vaginal secretions. Although fluid from a cotton swab can be smeared onto $\mathrm{pH}$ paper, the swabs are not ideal for measuring $\mathrm{pH}$ because they may not release enough fluid for an accurate reading.

Swabs can also easily become contaminated. "If the swab stayed in the air too long, if it was put on a surface or dropped, that would affect the reading." Sullivan says.

The researchers instead attached a four-inch strip of $\mathrm{pH}$ paper to a pediatric tongue depressor so that the measuring pad, which changes colors in response to the acidity of the environment, is at the tip. On either side is a color-coded pH key. "[The method] turned out to be very, very feasible," says Noah Kiwanuka, an investigator at the Rakai Health Sciences Program who oversaw the field work.

Once the researchers had proved that the swab worked, they set up an assembly line in Sullivan's dining room and convinced her three daughters, then between the ages of six and ten, to help. "One of them would open the tongue depressor package and pass it to the next, who would put the strip over the top, and then the third one would put the tape around and put it back in the bag," Sullivan says. 